include the influence of comorbid conditions, gender, family history, home environment, age, nutritional status; and effects of various treatments (stimulants, behavior therapy, parent training, school-based intervention) on different functions (cognitive, academic, behavioral), for how long (short versus long term), to what extent, and why? (Richters JE et al. NIMH collaborative multisite multimodal treatment study of children with ADHD: I. Background and rationale. IAm Acad Child Adolesc Psychiatry August 1995;34:987-1000).

\title{
KLUVER-BUCY SYNDROME FOLLOWING HEAT STROKE
}

A 12-year-old girl who developed a typical Kluver-Bucy syndrome (KBS) following heat stroke is reported from the University of Minnesota and Gillette Children's Hospital, Minneapolis, MN. The child collapsed and had a $20 \mathrm{~min}$ generalized seizure at the end of a 2 mile race run in 40-44 $\mathrm{C}$ ambient temperature. Cardiopulmonary resuscitation was necessary during a brief apnea. After iced normal saline infused during transport to the ER her rectal temperature was $102.7 \mathrm{~F}$. Twelve days later she had bowel and bladder incontinence, her affect was flat, she examined objects orally and attempted to eat them, she had no language and could not imitate sounds or words, she could not identify objects, she did not recognize family members, she had marked motor restlessness. After 4 weeks, she was extremely distractible and had limited visual attention. She was unable to dress herself. She was absorbed with her body. Hypersexuality was demonstrated by moving and dancing suggestively, masturbating, and rubbing against objects. She attempted to sit on the lap of adults and to kiss adults of both sexes. Several weeks later, she developed aggressive behaviors. At discharge, she required constant supervision and was dependent on others for all daily needs. MRI at 11 months after heat stroke showed mild, diffuse atrophy. Fourteen months after onset, she did not respond consistently to language, did not communicate verbally, and was dependent on others. (Pitt DC, Kriel RL et al. Kluver-Bucy syndrome following heat stroke in a 12-year-old girl. Pediatr Neurol July/August 1995;13:73-76). (Respond: Dr Kriel, Hennepin County Medical Center \#867-B, 701 Park Avenue South, Minneapolis, MN 55415).

COMMENT. The features of Kluver-Bucy syndrome include visual agnosia, hypermetamorphosis (distortion of objects), hypersexuality, language disorder and aphasia, hyperorality, placidity, flat affect, and memory dysfunction. The authors concluded that a metabolic/anoxic encephalopathy associated with heat stroke was the cause of the KBS in this child. In 12 additional reports cited from the literature, anoxic encephalopathy was the most commonly identified cause.

This article is especially appropriate during this exceptionally hot summer. Young athletes should be warned of possible serious consequences of exercise and heat stroke.

\section{PERCEPTUAL-MOTOR DEFICITS AND CONGENITAL MD}

Fine motor and perceptuo-motor abilities in 22 children with congenital muscular dystrophy, with and without MRI changes, were evaluated at the Hammersmith Hospital, London, UK. Perceptuo-motor difficulties and minor neurological soft signs were present in those with diffuse MRI changes but not in those with normal MRI. (Mercuri E et al. Minor neurological and perceptuo-motor deficits in children with congenital muscular dystrophy: Correlation with brain MRI changes. Neuropediatrics June 1995;26:156-162). 